\title{
On the Weak Stability of Picard Iteration for Some Contractive Type Mappings and Coincidence Theorems
}

\author{
loana Timis \\ Department of Mathematics and \\ Informatics \\ North University of Baia Mare \\ Victoriei 76, 430122, Baia Mare, \\ Romania
}

\begin{abstract}
Starting from a weak concept of stability, introduced by Berinde [1] and called "weak stability", in [27] we develop a weaker notion, named " $\mathrm{w}^{2}$-stability". Therefore, in this paper we prove some results of this weaker stability concept for certain class of mappings and also we give some examples of $\mathrm{w}^{2}$-stable but not weak stable nor stable iterations.
\end{abstract}

Because of the restriction of an "approximate" sequence, some fixed point iteration procedures are not weakly stable so if it is used a weaker type of sequence, the stability can be obtained in the meaning of a new concept.

\section{General Terms}

Fixed-point and coincidence theorems.

\section{Keywords}

Coincidence point, fixed point, stable iteration, weak stable iteration

\section{INTRODUCTION}

For the complete metric space $(X, d)$, with $x, y \in X$ and $x \neq y$, Harder [7], [8] presented some mappings $T: X \rightarrow X$ satisfying various contraction conditions for which the associated Picard iteration is not stable.

Their corresponding conditions in the case of two mappings $S$, $T: X \rightarrow X$ such that $T(X) \subseteq S(X)$, with $x, y \in X$ and $x \neq y$, are in the following form:
(1) $d(T x, T y)<\max \{d(S x, T x), d(S y, T y)\}$
(2) $d(T x, T y)<\max \{d(S x, T x), d(S y, T y), d(S x, S y)\}$
(3) $d(T x, T y)<\max \{d(S x, T x), d(S y, T y), d(S x, S y), d(S x, T y)$, $d(S y, T x)\}$
(4) $d(T x, T y)<\max \{d(S x, T x), d(S y, T y), d(S x, S y)$, $\frac{d(S x, T y)+d(S y, T x)}{2}$

Berinde [1] introduced the notion of weak stability and in [28] there is a study of weak stability of iterative procedures for some coincidence theorems. Moreover, Timis [27] introduced a weaker concept, called $\mathrm{w}^{2}$-stability, and gave weak stability results of Picard iteration for various contractive mappings defined by Harder [7], [8].

In this paper, we give $\mathrm{w}^{2}$-stability results of Picard iteration for mappings with a coincidence point satisfying conditions (1)-(4).

\section{WEAK STABILITY OF FIXED POINT ITERATION PROCEDURES}

One of the most general contractive definition for which corresponding stability results have been obtained in the case of Kirk, Mann and Ishikawa iteration procedures in arbitrary Banach spaces appears to be the following class of mappings: for $(X, d)$ a metric space, $T: X \rightarrow X$ is supposed to satisfy the condition

$$
d(T x, T y) \leq a d(x, y)+L d(x, T x),
$$

for some $a \in[0,1), L \geq 0$ and for all $x, y \in D \subseteq X$. This condition appears in [15] and other related results may be found in [14], [19], [20].

The concept of stability is not very precise because of the sequence $\left\{y_{n}\right\}_{n=0}^{\infty}$ which is arbitrary taken. So, it would be more natural that $\left\{y_{n}\right\}$ to be an approximate sequence of $\left\{x_{n}\right\}$ and Berinde [1] introduced the notion named "weak stability". Therefore, any stable iteration will be also weakly stable but the reverse is not generally true.

Because some contractive conditions are very strictly and the associated fixed point iteration is not weakly stable, Timis [27] used equivalent sequences in order to introduce the notion of $\mathrm{w}^{2}$-stability.

In the following, we restate the definition of $\mathrm{w}^{2}$-stability for the case of two self-mappings with a coincidence point and using this, we establish stability results for common fixed point iterative procedures in the class of mappings that satisfy the above contraction conditions (1)-(4).

Definition 2.1. Let the map $S: X \rightarrow X$ and $(X, d)$ to be a metric space. Two sequences $\left\{x_{n}\right\}_{n=0}^{\infty}$ and $\left\{y_{n}\right\}_{n=0}^{\infty}$ are called Sequivalent sequences if $d\left(S x_{n}, S y_{n}\right) \rightarrow 0$, as $n \rightarrow \infty$.

Definition 2.2. Let $(X, d)$ be a metric space, $S, T: X \rightarrow X$ be two maps such as $T(X) \subseteq S(X)$ and $z$ is a coincidence point of $S$ and $T$, that is a point for which we have $S z=T z=u \in X$. Let $\left\{S x_{n}\right\}$ be an iteration procedure defined by $x_{0} \in X$ and $S x_{n+1}=f\left(T, x_{n}\right), n \geq 0$.

Suppose that $\left\{S x_{n}\right\}$ converges to $u$. If for any equivalent sequence $\left\{S y_{n}\right\} \in X$ of $\left\{S x_{n}\right\}$,

$\lim _{n \rightarrow \infty} d\left(S y_{n+1}, T y_{n}\right)=0$, implies that $\lim _{n \rightarrow \infty} S y_{n}=u$,

then we shall say that the iteration procedure is $\mathrm{w}^{2}$-stable with respect to $(S, T)$. 
We mention that the concept of $(S, T)$-stability was used in [26] and the transposition to $(S, T)$-weak stability in a metric space was introduced in [28].

\section{MAIN RESULTS}

The basic results of this paper are the following theorems:

Theorem 3.1. Let $(X, d)$ be a complete metric space and $S, T$ : $X \rightarrow X$ be two maps such that $T(X) \subseteq S(X)$, satisfying (1), i.e., $d(T x, T y)<\max \{d(S x, T x), d(S y, T y)\}$, for all $x, y \in X$ and $x \neq y$.

Let $\left\{S x_{n}\right\}_{n=0}^{\infty}$ be an iterative procedure defined by $x_{0} \in X$ and $S x_{n+1}=T x_{n}$, for all $n \geq 0$ and the sequence $\left\{S x_{n}\right\}$ converges to $u$, where $u$ is a coincidence point of $S$ and $T$.

Then, the Picard iteration is $\mathrm{w}^{2}$-stable.

Proof. Consider $\left\{S y_{n}\right\}_{n=0}^{\infty}$ to be an equivalent sequence of $\left\{S x_{n}\right\}$. Then, according to Definition 2.2., if $\lim _{n \rightarrow \infty} d\left(S y_{n+1}, T y_{n}\right)=0$ implies that $\lim _{n \rightarrow \infty} S y_{n}=u$, then the Picard iteration is $\mathrm{w}^{2}$-stable.

In order to prove this, we suppose that $\lim _{n \rightarrow \infty} d\left(S y_{n+1}, T y_{n}\right)=0$. Therefore, for all $\varepsilon>0$, there exists $n_{0}=n(\varepsilon)$ such that $d\left(S y_{n+1}, T y_{n}\right)<\varepsilon$, for all $n \geq n_{0}$.

So, $\quad d\left(S y_{n+1}, u\right) \leq d\left(S y_{n+1}, S x_{n+1}\right)+d\left(S x_{n+1}, u\right) \leq$ $d\left(S y_{n+1}, T y_{n}\right)+d\left(T y_{n}, T x_{n}\right)+d\left(S x_{n+1}, u\right)<$

$d\left(S y_{n+1}, T y_{n}\right)+\max \left\{d\left(S x_{n}, T x_{n}\right), d\left(S y_{n}, T y_{n}\right)\right\}+$

$d\left(S x_{n+1}, u\right)$.

From the hypothesis, by $S x \rightarrow u$, we have that $d\left(S x_{n}, T x_{n}\right)=$ $d\left(S x_{n}, S x_{n+1}\right) \leq d\left(S x_{n}, u\right)+d\left(u, S x_{n+1}\right) \rightarrow 0$.

If $\max \left\{d\left(S x_{n}, T x_{n}\right), d\left(S y_{n}, T y_{n}\right)\right\}=d\left(S x_{n}, T x_{n}\right)$, by taking to the limit, we obtain that $d\left(S y_{n+1}, u\right) \rightarrow 0$.

If $\max \left\{d\left(S x_{n}, T x_{n}\right), d\left(S y_{n}, T y_{n}\right)\right\}=d\left(S y_{n}, T y_{n}\right)$, we have that $\quad d\left(S y_{n}, T y_{n}\right) \leq d\left(S y_{n}, S x_{n}\right)+d\left(S x_{n}, S x_{n+1}\right)+$ $d\left(S x_{n+1}, S y_{n+1}\right)+d\left(S y_{n+1}, T y_{n}\right)$.

From Definition 2.1., $d\left(S y_{n}, S x_{n}\right) \rightarrow 0$ and by taking to the limit, we obtain that $d\left(S y_{n+1}, u\right) \rightarrow 0$.

This shows that the Picard iteration is $\mathrm{w}^{2}$-stable with respect to $(S, T)$.

Theorem 3.2. Let $(X, d)$ be a complete metric space and $S, T$ : $X \rightarrow X$ such that $T(X) \subseteq S(X)$, satisfying (2), i.e., $d(T x, T y)<\max \{d(S x, T x), d(S y, T y), d(S x, S y)\}$, for all $x, y \in X$ and $x \neq y$.

Let $\left\{S x_{n}\right\}_{n=0}^{\infty}$ be an iterative procedure defined by $x_{0} \in X$ and $S x_{n+1}=T x_{n}$, for all $n \geq 0$ and the sequence $\left\{S x_{n}\right\}$ converges to $u$, where $u$ is a coincidence point of $S$ and $T$.

Then, the Picard iteration is $\mathrm{w}^{2}$-stable.

Proof. We follow the same assumptions as in Theorem 3.1., by taking $\left\{S y_{n}\right\}_{n=0}^{\infty}$ to be an equivalent sequence of $\left\{S x_{n}\right\}$. By Definition 2.2, if $\lim _{n \rightarrow \infty} d\left(S y_{n+1}, T y_{n}\right)=0$ implies that $\lim _{\mathrm{n} \rightarrow \infty} S y_{n}=u$, then the Picard iteration is $\mathrm{w}^{2}$-stable.

Theorem 3.1. shows this result if we consider $\max \{d(S x, T x), d(S y, T y)\}$. In this case, there is a new situation, when $\max$ could be $d(S x, S y)$.

Therefore, following the same steps, we get that $\max \left\{d\left(S x_{n}, T x_{n}\right), d\left(S y_{n}, T y_{n}\right), d\left(S x_{n}, S y_{n}\right)\right\}=d\left(S x_{n}, S y_{n}\right)$. From Definition 2.1., we have that $d\left(S y_{n}, S x_{n}\right) \rightarrow 0$ and by taking to the limit as it is shown in the above theorem, we obtain the conclusion.
Theorem 3.3. Let $(X, d)$ be a complete metric space and $S, T$ : $X \rightarrow X$ such that $T(X) \subseteq S(X)$, satisfying (3), i.e., $d(T x, T y)<\max \{d(S x, T x), d(S y, T y), d(S x, S y), d(S x, T y), d(S y, T x)\}$, for all $x, y \in X$ and $x \neq y$.

Let $\left\{S x_{n}\right\}_{n=0}^{\infty}$ be an iterative procedure defined by $x_{0} \in X$ and $S x_{n+1}=T x_{n}$, for all $n \geq 0$ and the sequence $\left\{S x_{n}\right\}$ converges to $u$, where $u$ is a coincidence point of $S$ and $T$.

Then, the Picard iteration is $\mathrm{w}^{2}$-stable.

Proof. We follow the same assumptions as in Theorem 3.2., where is shown this result if we consider $\max \{d(S x, T x), d(S y, T y), d(S x, S y)\}$. In this case, there are new situations, when max could be $d(S x, T y)$ or $d(S y, T x)$. Again, we follow the same steps.

If $\max$ is $d\left(S x_{n}, T y_{n}\right)$, we have that $d\left(S x_{n}, T y_{n}\right) \leq$ $d\left(S x_{n}, S y_{n}\right)+d\left(S y_{n}, T y_{n}\right) . \quad$ From Definition 2.1., |ref $\{$ Def_S_ech $\}, d\left(S y_{n}, S x_{n}\right) \rightarrow 0$ and the expression of $d\left(S y_{n}, T y_{n}\right)$ was treated in Theorem 3.1.

On the other hand, if $\max$ is $d\left(S y_{n}, T x_{n}\right)$, then $d\left(S y_{n}, T x_{n}\right) \leq d\left(S y_{n}, S x_{n}\right)+d\left(S x_{n}, T x_{n}\right)$.

By taking to the limit in a same way as in above theorems, we obtain the conclusion.

Theorem 3.4. Let $(X, d)$ be a complete metric space and $S, T$ : $X \rightarrow X$ such that $T(X) \subseteq S(X)$, satisfying (4), i.e.,

$d(T x, T y)<\max \left\{d(S x, T x), d(S y, T y), d(S x, S y), \frac{d(S x, T y)+d(S y, T x)}{2}\right\}$

for all $x, y \in X$ and $x \neq y$.

Let $\left\{S x_{n}\right\}_{n=0}^{\infty}$ be an iterative procedure defined by $x_{0} \in X$ and $S x_{n+1}=T x_{n}$, for all $n \geq 0$ and the sequence $\left\{S x_{n}\right\}$ converges to $u$, where $u$ is a coincidence point of $S$ and $T$.

Then, the Picard iteration is $\mathrm{w}^{2}$-stable.

Proof. We follow the same assumptions as in Theorem 3.3., where is shown this result if we consider $\max \{d(S x, T x), d(S y, T y), d(S x, S y), d(S x, T y), d(S y, T x)\}$.

In this case, this is a new situation, when max could be $\frac{d(S x, T y)+d(S y, T x)}{2}$. Then, following the same steps as in Theorem 3.3., we obtain that $d\left(S x_{n}, T y_{n}\right) \rightarrow 0$ and $d\left(S y_{n}, T x_{n}\right) \rightarrow 0$, so, by taking to the limit in the whole expression, we get the result.

From Theorem 3.3., we obtain the following stability result.

Corollary 3.5. Let $(X, d)$ be a complete metric space and $S, T$ : $X \rightarrow X$ two mappings such that $T(X) \subseteq S(X)$, satisfying

(5) $d(T x, T y)<\max \{d(S x, T y), d(S y, T x)\}$,

for all $x, y \in X$ and $x \neq y$.

Let $\left\{S x_{n}\right\}_{n=0}^{\infty}$ be an iterative procedure defined by $x_{0} \in X$ and $S x_{n+1}=T x_{n}$, for all $n \geq 0$ and the sequence $\left\{S x_{n}\right\}$ converges to $u$, where $u$ is a coincidence point of $S$ and $T$.

Then, the Picard iteration is $\mathrm{w}^{2}$-stable.

\section{EXAMPLES}

In the following, we present some examples of mappings that satisfy contraction conditions and for which the associated Picard iteration is not $(S, T)$-stable, it is not $(S, T)$-weakly stable but it is $(S, T)$ - $\mathrm{w}^{2}$-stable. 
Example 4.1. Let $S, T:[0,1] \rightarrow[0,1]$ be given by

$T x=\left\{\begin{array}{ll}0, & x \in\left[0, \frac{1}{2}\right] \\ \frac{1}{2}, & x \in\left(\frac{1}{2}, 1\right]\end{array}\right.$ and $S x=\left\{\begin{array}{ll}\frac{1}{2}-x, & x \in\left[0, \frac{1}{2}\right] \\ x-\frac{1}{4}, & x \in\left(\frac{1}{2}, 1\right]\end{array}\right.$, where

$[0,1]$ is endowed with the usual metric. $S$ and $T$ are continuous at every point of $[0,1]$ except at $\frac{1}{2}$, which is their coincidence point, i.e., $T\left(\frac{1}{2}\right)=S\left(\frac{1}{2}\right)=0=u$ and $T([0,1])=\left\{0, \frac{1}{2}\right\} \subseteq S([0,1])=\left[0, \frac{1}{2}\right] \cup\left(\frac{1}{4}, \frac{3}{4}\right]=\left[0, \frac{3}{4}\right]$.

For each $x, y \in[0,1], x \neq y, T$ and $S$ satisfy the condition (5), i.e., $d(T x, T y)<\max \{d(S x, T y), d(S y, T x)\}$.

Indeed, first let $x \in\left[0, \frac{1}{2}\right], y \in\left[0, \frac{1}{2}\right]$ and $x \neq y$.

Then, $|T x-T y|=0<\max \left\{\left|\frac{1}{2}-x-0\right|,\left|\frac{1}{2}-x-0\right|\right\}$.

If $x \in\left(\frac{1}{2}, 1\right], y \in\left(\frac{1}{2}, 1\right]$ and $x \neq y$, then

$|T x-T y|=0<\max \left\{\left|x-\frac{1}{4}-\frac{1}{2}\right|,\left|y-\frac{1}{4}-\frac{1}{2}\right|\right\}$.

If $x \in\left[0, \frac{1}{2}\right]$ and $y \in\left(\frac{1}{2}, 1\right]$, then

$|T x-T y|=\left|0-\frac{1}{2}\right|=\frac{1}{2}<\max \left\{\left|\frac{1}{2}-x-\frac{1}{2}\right|, \mid y-\frac{1}{4}-\right.$

$0 \mid\}=\max \left\{|x|,\left|y-\frac{1}{4}\right|\right\}$.

We will show that the Picard iteration is not $(S, T)$-stable, it is not $(S, T)$-weakly stable but it is $(S, T)$ - $\mathrm{w}^{2}$-stable.

In order to prove the first claim, let $\left(S y_{n}\right)$, with $S y_{n}=\frac{n+2}{2 n}$, $n \geq 1$. Then $\varepsilon_{n}=\left|S y_{n+1}-T y_{n}\right|=\left|\frac{n+3}{2(n+1)}-\frac{1}{4}-\frac{1}{2}\right|$, because $S y_{n}>\frac{1}{2}$, for $n \geq 1$.

According to $(S, T)$-stability definition of [26], assuming that $\lim _{\mathrm{n} \rightarrow \infty} \varepsilon_{n}=0$, we should obtain that $\lim _{\mathrm{n} \rightarrow \infty} S y_{n}=\frac{3}{4}$, but in fact, $\lim _{\mathrm{n} \rightarrow \infty} S y_{n}=\frac{1}{2}$, so the Picard iteration is not $(S, T)$ stable.

In order to study the $(S, T)$-weak stability, from the $(S, T)$-weak stability definition of [28], we take an approximate sequence $\left\{S y_{n}\right\}$ of $\left(S x_{n}\right)$. Then, there exists a decreasing sequence of nonnegative numbers $\left\{\eta_{n}\right\}$ converging to some $\eta \geq 0$, for $n \rightarrow \infty$, such that $\left|S x_{n}-S y_{n}\right| \leq \eta_{n}, n \geq k$.

Then, $-\eta_{n} \leq S x_{n}-S y_{n} \leq \eta_{n}$ and it results that $0 \leq S y_{n} \leq$ $S x_{n}+\eta_{n}, n \geq k$.

If $x_{0} \in\left[0, \frac{1}{2}\right], S x_{1}=T x_{0}=0$, therefore $S x_{n}=0, n \geq 1$. On the other hand, if $x_{0} \in\left(\frac{1}{2}, 1\right]$, then $S x_{1}=T x_{0}=\frac{1}{2}$ and $S x_{2}=$ $T x_{1}=0$, so $S x_{n}=0, n \geq 2$.

If $x_{n} \in\left[0, \frac{1}{2}\right]$, then $S x_{n}=\frac{1}{2}-x_{n}$. So, $0 \leq x_{n} \leq \frac{1}{2} \Leftrightarrow 0 \geq$ $-x_{n} \geq-\frac{1}{2} \Leftrightarrow \frac{1}{2} \geq \frac{1}{2}-x_{n} \geq 0 \Leftrightarrow 0 \leq \frac{1}{2}-x_{n}=S x_{n} \leq \frac{1}{2}$.

Hence, in this situation, $S x_{n}$ can have the value of 0 .

If $x_{n} \in\left(\frac{1}{2}, 1\right]$, then $S x_{n}=x_{n}-\frac{1}{4}$. So, $\frac{1}{2}<x_{n} \leq 1 \Leftrightarrow \frac{1}{4}<$ $x_{n}-\frac{1}{4}=S x_{n} \leq \frac{3}{4}$. In this case, $S x_{n}$ can not be 0 .

Therefore, $x_{n} \in\left[0, \frac{1}{2}\right]$ and then, $T x_{n}=0$.
Since $S x_{n}=0$, for $n \geq 2$, we obtain that $0 \leq S y_{n} \leq \eta_{n}, n \geq$ $k_{1}=\max \{2, k\}$. We can choose $\left\{\eta_{n}\right\}$ such that $\eta_{n} \leq \frac{1}{2}$, $\mathrm{n} \geq k_{1}$ and therefore $0 \leq S y_{n} \leq \frac{1}{2}, \forall n \geq k_{1}$.

If $y_{n} \in\left[0, \frac{1}{2}\right]$, then $S y_{n}=\frac{1}{2}-y_{n}$, so, $0 \leq y_{n} \leq \frac{1}{2} \Leftrightarrow 0 \geq$ $-y_{n} \geq-\frac{1}{2} \Leftrightarrow-\frac{1}{2} \leq-y_{n} \leq 0 \Leftrightarrow 0 \leq \frac{1}{2}-y_{n}=S y_{n} \leq \frac{1}{2}$, situation that can be possible. In this case, we have that $T y_{n}=0$.

If $y_{n} \in\left(\frac{1}{4}, \frac{3}{4}\right] \cap\left(\frac{1}{2}, 1\right]=\left(\frac{1}{2}, \frac{3}{4}\right], \quad$ then $S y_{n}=y_{n}-\frac{1}{4}, \quad$ so, $\frac{1}{2}<y_{n} \leq \frac{3}{4} \Leftrightarrow \frac{1}{4}<y_{n}-\frac{1}{4}=S y_{n} \leq \frac{1}{2}$,

and this can be possible, too. Hence, for $y_{n} \in\left(\frac{1}{2}, \frac{3}{4}\right]$, we have that $T y_{n}=\frac{1}{2}$.

If $d\left(S y_{n+1}, T y_{n}\right) \rightarrow 0$ implies that $d\left(S y_{n}, u\right) \rightarrow 0$, for $n \rightarrow \infty$, the $(S, T)$-weak stability should be obtained.

If $y_{n} \in\left[0, \frac{1}{2}\right]$, then from $d\left(S y_{n+1}, T y_{n}\right)=d\left(S y_{n+1}, 0\right) \rightarrow 0$, we obtain that $S y_{n+1} \rightarrow 0$ but if $y_{n} \in\left(\frac{1}{2}, \frac{3}{4}\right]$, then from $d\left(S y_{n+1}, T y_{n}\right)=d\left(S y_{n+1}, \frac{1}{2}\right) \rightarrow 0$, we obtain that $S y_{n+1} \rightarrow$ $\frac{1}{2}$, so $S y_{n} \rightarrow \frac{1}{2}$. Therefore, the Picard iteration is not $(S, T)$ weakly stable.

In order to study the $\mathrm{w}^{2}$-stability with respect to $(S, T)$, from Definition 2.2., we should have that $\lim _{n \rightarrow \infty} \mathrm{d}\left(\mathrm{Sy}_{\mathrm{n}+1}, \mathrm{Ty}_{\mathrm{n}}\right)=$ 0 , implies that $\lim _{n \rightarrow \infty} S y_{n}=u$.

Let an equivalent sequence $\left\{S y_{n}\right\}$ of $S x_{n}$ and by Definition 2.1., $d\left(S x_{n}, S y_{n}\right) \rightarrow 0$, as $n \rightarrow \infty$.

So, $d\left(S y_{n}, u\right) \leq d\left(S y_{n}, S x_{n}\right)+d\left(S x_{n}, u\right)=d\left(S y_{n}, S x_{n}\right) \rightarrow 0$ and this proves the $\mathrm{w}^{2}$-stability with respect to $(S, T)$.

Example 4.2. Let $S, T:[0,1] \rightarrow[0,1]$ be given by

$T x=\left\{\begin{array}{ll}\frac{x+1}{2}, & x \in\left[0, \frac{1}{2}\right] \\ \frac{1}{2}, & x \in\left(\frac{1}{2}, 1\right]\end{array}\right.$ and $S x=\left\{\begin{array}{ll}\frac{1}{2}-x, & x \in\left[0, \frac{1}{2}\right] \\ x-\frac{1}{4}, & x \in\left(\frac{1}{2}, 1\right]\end{array}\right.$, where

$[0,1]$ is endowed with the usual metric.

$S$ and $T$ have two coincidence points, i.e., $T(0)=S(0)=$ $T\left(\frac{3}{4}\right)=S\left(\frac{3}{4}\right)=\frac{1}{2}=u$ and $T([0,1])=\left[\frac{1}{2}, \frac{\frac{1}{2}+1}{2}\right] \cup\left\{\frac{1}{2}\right\}=$ $\left[\frac{1}{2}, \frac{3}{4}\right] \subseteq S([0,1])=\left[0, \frac{1}{2}\right] \cup\left(\frac{1}{4}, \frac{3}{4}\right]=\left[0, \frac{3}{4}\right]$.

For each $x, y \in[0,1], x \neq y, T$ and $S$ satisfy the condition (5), i.e., $d(T x, T y)<\max \{d(S x, T y), d(S y, T x)\}$.

Indeed, first let $x \in\left[0, \frac{1}{2}\right], y \in\left[0, \frac{1}{2}\right]$ and $x \neq y$.

Then, $\quad|T x-T y|=\left|\frac{x}{2}+\frac{1}{2}-\frac{y}{2}-\frac{1}{2}\right|=\frac{1}{2}|x-y|=\left[0, \frac{1}{4}\right]<$ $\max \left\{\left|\frac{1}{2}-x-\frac{y}{2}-\frac{1}{2}\right|,\left|\frac{1}{2}-y-\frac{x}{2}-\frac{1}{2}\right|\right\}=\max \left\{\left|x+\frac{y}{2}\right|, \mid y+\right.$ $\left.\frac{x}{2} \mid\right\}=\max \left\{\left[0, \frac{1}{2}\right]+\left[0, \frac{1}{4}\right],\left[0, \frac{1}{2}\right]+\left[0, \frac{1}{4}\right]\right\}=$ $\max \left\{\left[0, \frac{3}{4}\right],\left[0, \frac{3}{4}\right]\right\}=\left[0, \frac{3}{4}\right]$.

If $x \in\left(\frac{1}{2}, 1\right], y \in\left(\frac{1}{2}, 1\right]$ and $x \neq y$, then

$|T x-T y|=0<\max \left\{\left|x-\frac{1}{4}-\frac{1}{2}\right|,\left|y-\frac{1}{4}-\frac{1}{2}\right|\right\}=$ $\max \left\{\left|x-\frac{3}{4}\right|,\left|y-\frac{3}{4}\right|\right\}=\left[0, \frac{1}{4}\right]$. 
If $x \in\left[0, \frac{1}{2}\right]$ and $y \in\left(\frac{1}{2}, 1\right]$, then

$|T x-T y|=\left|\frac{x}{2}+\frac{1}{2}-\frac{1}{2}\right|=\frac{1}{2}|x|=\left[0, \frac{1}{4}\right]<\max \left\{\mid \frac{1}{2}-x-\right.$ $\left.\frac{1}{2}|| y-,\frac{1}{4}-\frac{x}{2}-\frac{1}{2} \mid\right\}=\max \left\{|x|,\left|y-\frac{x}{2}-\frac{3}{4}\right|\right\}=$ $\max \left\{\left[0, \frac{1}{2}\right],\left(\frac{1}{2}, 1\right]-\left[0, \frac{1}{4}\right]-\frac{3}{4}=\left[0, \frac{1}{4}\right]\right\}=\left[0, \frac{1}{2}\right]$.

We will show that the Picard iteration is not $(S, T)$-stable, it is not $(S, T)$-weakly stable but it is $(S, T)$ - $\mathrm{w}^{2}$-stable.

In order to prove the first claim, let $\left(S y_{n}\right)$, with $S y_{n}=\frac{n+2}{2 n}$, $n \geq 1$. Then $\varepsilon_{n}=\left|S y_{n+1}-T y_{n}\right|=\left|\frac{n+3}{2(n+1)}-\frac{1}{4}-\frac{1}{2}\right|$, because $S y_{n}>\frac{1}{2}$, for $n \geq 1$.

According to $(S, T)$-stability definition of [26], assuming that $\lim _{\mathrm{n} \rightarrow \infty} \varepsilon_{n}=0$, we should obtain that $\lim _{\mathrm{n} \rightarrow \infty} S y_{n}=\frac{3}{4}$, but in fact, $\lim _{\mathrm{n} \rightarrow \infty} S y_{n}=\frac{1}{2}$, so the Picard iteration is not $(S, T)$ stable.

For the $(S, T)$-weak stability, from the $(S, T)$-weak stability definition of [28], for any $x_{0} \in[0,1]$, the sequence $\left\{S x_{n}\right\}$ generated by the iterative procedure $S x_{n+1}=T x_{n}, n>0$, converges to $u=\frac{1}{2}$.

Indeed, if $x_{0} \in\left[0, \frac{1}{2}\right]$, then $S x_{1}=T x_{0}=\frac{x_{0}+1}{2} \in \frac{\left[0, \frac{1}{2}\right]+1}{2}=$ $\frac{\left[1, \frac{3}{2}\right]}{2}=\left[\frac{1}{2}, \frac{3}{4}\right] . \quad$ Now, if $x_{1} \in\left[0, \frac{1}{2}\right]$, then $S x_{1}=\frac{1}{2}-x_{1} \in \frac{1}{2}-$ $\left[0, \frac{1}{2}\right]=\left[0, \frac{1}{2}\right]$. Only for $x_{1}=0$, we have that $S x_{2}=T x_{1}=\frac{1}{2}$, so, $S x_{n}=T x_{n}=\frac{1}{2}, \forall n \geq 2$.

On the other hand, if $x_{1} \in\left(\frac{1}{2}, 1\right]$, then $S x_{1}=x_{1}-\frac{1}{4} \in$ $\left(\frac{1}{2}, 1\right]-\frac{1}{4}=\left(\frac{1}{4}, \frac{3}{4}\right]$. Only for $x_{1} \in\left(\frac{3}{4}, 1\right]$, we have that $S x_{1} \in\left(\frac{1}{2}, \frac{3}{4}\right]$. Hence, $S x_{2}=T x_{1}=\frac{1}{2}$, so, $S x_{n}=T x_{n}=\frac{1}{2}, \forall$ $n \geq 2$.

If $x_{0} \in\left(\frac{1}{2}, 1\right]$, then $S x_{1}=T x_{0}=\frac{1}{2}$, so, $S x_{n}=T x_{n}=\frac{1}{2}, \forall$ $n \geq 1$.

We take an approximate sequence $\left\{S y_{n}\right\}$ of $S x_{n}$. Then, there exists a decreasing sequence of nonnegative numbers $\left\{\eta_{n}\right\}$ converging to some $\eta \geq 0$, for $n \rightarrow \infty$, such that $\left|S x_{n}-S y_{n}\right| \leq$ $\eta_{n}, n \geq k$.

Then, $-\eta_{n} \leq S x_{n}-S y_{n} \leq \eta_{n}$ and it results that $0 \leq S y_{n} \leq$ $S x_{n}+\eta_{n}, n \geq k$.

Since $S x_{n}=\frac{1}{2}$, for $n \geq 2$, we obtain that $0 \leq S y_{n} \leq \frac{1}{2}+\eta_{n}$, $n \geq k_{1}=\max \{2, k\}$. We can choose $\left\{\eta_{n}\right\}$ such that $\eta_{n} \leq \frac{1}{4}$, $\mathrm{n} \geq k_{1}$ and therefore $0 \leq S y_{n} \leq \frac{3}{4}, \forall n \geq k_{1}$.

If $d\left(S y_{n+1}, T y_{n}\right) \rightarrow 0$ implies that $d\left(S y_{n}, u\right) \rightarrow 0$, for $n \rightarrow \infty$, the $(S, T)$-weak stability should be obtained.

If $y_{n} \in\left(\frac{1}{2}, 1\right] \cap\left(\frac{1}{4}, \frac{3}{4}\right]=\left(\frac{1}{2}, \frac{3}{4}\right]$, then $S y_{n}=y_{n}-\frac{1}{4} \in\left(\frac{1}{2}, \frac{3}{4}\right]-$ $\frac{1}{4}=\left(\frac{1}{4}, \frac{1}{2}\right] \in\left[0, \frac{3}{4}\right]$ and $T y_{n}=\frac{1}{2}$. From $d\left(S y_{n+1}, T y_{n}\right)=$ $d\left(S y_{n+1}, \frac{1}{2}\right) \rightarrow 0$, we obtain that $S y_{n+1} \rightarrow \frac{1}{2}$, so $S y_{n} \rightarrow \frac{1}{2}=u$, but if $y_{n} \in\left[0, \frac{1}{2}\right]$, then $S y_{n}=\frac{1}{2}-y_{n}=\frac{1}{2}-\left[0, \frac{1}{2}\right]=\left[0, \frac{1}{2}\right] \in$ $\left[0, \frac{3}{4}\right]$ and $T y_{n}=\frac{y_{n}+1}{2} \in \frac{1}{2}\left[1, \frac{3}{2}\right]=\left[\frac{1}{2}, \frac{3}{4}\right]$.
Therefore, $d\left(S y_{n+1}, T y_{n}\right)=\left|\left[0, \frac{1}{2}\right]-\left[\frac{1}{2}, \frac{3}{4}\right]\right|=\left[\frac{1}{4}, \frac{1}{2}\right]$ and then $\lim _{n \rightarrow \infty} \mathrm{d}\left(\mathrm{Sy}_{\mathrm{n}+1}, \mathrm{Ty}_{\mathrm{n}}\right)$ can not be 0 . Therefore, the Picard iteration is not $(S, T)$-weakly stable.

In order to study the $\mathrm{w}^{2}$-stability with respect to $(S, T)$, from Definition 2.2., we should have that $\lim _{n \rightarrow \infty} \mathrm{d}\left(\mathrm{Sy}_{\mathrm{n}+1}, \mathrm{Ty}_{\mathrm{n}}\right)=$ 0 , implies that $\lim _{n \rightarrow \infty} \mathrm{Sy}_{\mathrm{n}}=u$.

Let an equivalent sequence $\left\{S y_{n}\right\}$ of $S x_{n}$ and by Definition 2.1., $d\left(S x_{n}, S y_{n}\right) \rightarrow 0$, as $n \rightarrow \infty$.

So, $d\left(S y_{n}, u\right) \leq d\left(S y_{n}, S x_{n}\right)+d\left(S x_{n}, u\right)=d\left(S y_{n}, S x_{n}\right) \rightarrow 0$ and this proves the $\mathrm{w}^{2}$-stability with respect to $(S, T)$.

\section{CONCLUSIONS}

The concept of stability is slightly not very precise because of the sequence $\left\{S y_{n}\right\}_{n=0}^{\infty}$ which is arbitrary taken. From a numerical point of view, $\left\{S y_{n}\right\}_{n=0}^{\infty}$ must be an approximate sequence of $\left\{S x_{n}\right\}_{n=0}^{\infty}$.

By adopting a concept of such kind of approximate sequences, Berinde [1] introduced a weaker and more natural concept of stability, called weak stability. So, any stable iteration will be also weakly stable but the reverse is not generally true.

But using an approximate sequence in the definition of weak stability, some fixed point iteration procedures are not weakly stable but if it is used a weaker type of sequence, the stability can be obtained in the meaning of a new concept, named $\mathrm{w}^{2}$ stability.

Therefore, here we proved that for the class of mappings which satisfy some contraction conditions presented by Harder and Hicks [8] and for the class of mappings with a coincidence point, the associated Picard iterations are $\mathrm{w}^{2}$ stable.

We also gave some illustrative examples of mappings that satisfy contraction conditions and for which the associated Picard iteration is not $(S, T)$-stable, it is not $(S, T)$-weakly stable but it is $(S, T)$ - $\mathrm{w}^{2}$-stable.

\section{REFERENCES}

[1] Berinde, V. 2007. Iterative Approximation of Fixed Points. Springer Verlag, Lectures Notes in Mathematics.

[2] Berinde, V. 2002. On the stability of fixed point iteration procedures. Bul. Stiint. Univ. Baia Mare, Fasc.Mat.-Inf., vol. XVIII, no. 1, 7-12.

[3] Berinde, V. 2003. Summable almost stability of fixed point iteration procedures. Carpathian J. Math.19, no. 2, 81-88.

[4] Cardinali, T. and Rubbioni, P. 2010. A generalization of the Caristi fixed point theorem in metric spaces. Fixed Point Theory 11, no. 1, 3-10.

[5] Czerwik, S., Dlutek, K. and Singh, S.L. 1997. Round-off stability of iteration procedures for operators in b-metric spaces. J. Natur. Phys. Sci., 87-94.

[6] Harder, A.M. 1987. Fixed point theory and stability results for fixed point iteration procedures. Ph.D. thesis, University of Missouri-Rolla, Missouri.

[7] Harder, A.M. and Hicks, T.L. 1988. A stable iteration procedure for nonexpansive mappings. Math. Japon. 33, 687-692. 
[8] Harder, A.M. and Hicks, T.L. 1988. Stability results for fixed point iteration procedures. Math. Japon. 33, 693706.

[9] Jachymski, J. 1994. Common fixed point theorems for some families of maps. Indian J. Pure Appl. Math. 25, no. 9, 925-937.

[10] Jungck, G. 1988. Common fixed points for commuting and compatible maps on compacta. Proc. Amer. Math. Soc. $103,977-983$

[11] Jungck, G. 1976. Commuting mappings and fixed points Amer. Math. Monthly 83, no. 4, 261-263.

[12] Matkowski, J. and Singh, L. 1997. Round-off stability of functional iterations of product spaces. Indian J. Math. 39, no.3, 275-286

[13] Mishra, S.N. and Singh, S.L. 1996. Fixed point theorems in a locally convex space. Quaestiones Math. 19, no. 3-4, 505-515.

[14] Osilike, M.O. 1996. A stable iteration procedure for quasi-contractive maps. Indian J. Pure Appl. Math. 27(1), 25-34.

[15] Osilike, M.O. 1995. Stability results for fixed point iteration procedure. J. Nigerian Math. Soc. 14, 17-27.

[16] Ostrowski, A.M. 1967. The round-off stability of iterations. Z. Angew. Math. Mech. 47, no. 1, 77-81.

[17] Ranganathan, S. 1978. A fixed point for commuting mappings. Math. Sem. Notes Kobe Univ. 6, no. 2, 351357.

[18] Rhoades, B.E. 1977. A comparison of various definitions of contractive mappings. Trans. Amer. Math. Soc. 226, 257-290.

[19] Rhoades, B.E. 1990. Fixed point theorems and stability results for fixed point iteration procedures. Indian J. Pure Appl. Math. 21, no. 1, 1-9.
[20] Rhoades, B.E. 1993. Fixed point theorems and stability results for fixed point iteration procedures II. Indian J. Pure Appl. Math. 24, no. 11, 691-703.

[21] Rhoades, B.E. and Saliga, L. 2001. Some fixed point iteration procedures II. Nonlinear Anal. Forum 6(1), 193 217.

[22] Rus, I.A., Petrusel, A. and Petrusel, G. 2002. Fixed point theory 1950-2000: Romanian contribution. House of the Book of Science, Cluj-Napoca.

[23] Singh, S.L. 1978. Application of a common fixed point theorem. Math. Sem. Notes Kobe Univ. 6, no. 1, 37-40.

[24] Singh, S.L. 1986. Coincidence theorems, fixed point theorems and convergence of the sequences of coincidence values. Punjab Univ. J. Math. (Lahore) 19, 83-97.

[25] Singh, S.L., Bhatnagar, C. and Mishra, S.N. 2005. Stability of Jungck-type iterative procedures. Int. J. Math. Sci. 19, 3035-3043.

[26] Singh, S.L. and Prasad, B. 2008. Some coincidence theorems and stability of iterative procedures. Comp. and Math. with Appl. 55, 2512 - 2520.

[27] Timis, I. 2010. On the weak stability of Picard iteration for some contractive type mappings. Annals of the University of Craiova - Mathematics and Computer Science Series 37(2), 106-114.

[28] Timis, I. and Berinde, V. 2010. Weak stability of iterative procedures for some coincidence theorems. Creative Math. and Inf. 19, 85-95.

[29] Tivari, B.M.L. and Singh, S.L. 1986. A note on recent generalizations of Jungck contraction principle. J. Uttar Pradesh Gov. Colleges Acad. Soc. 3, no. 1, 13-18. 